TEAEs of interest were infections (40.8\%), liver enzyme elevations $(5.4 \%)$, and hypersensitivity $(4.3 \%)$.

Overall, $18.2 \%$ (85/466) of subjects developed binding antidrug antibodies (ADAs) and $6.9 \%(32 / 466)$ developed neutralizing ADAs in the OLE study. The rates of ADA formation were similar between subjects who transitioned from adalimumab and those who continued on ABP 501.

The ACR20 response rate (using the parent study baseline) was 73.3\% (340/464) at the OLE study baseline, $77.6 \%(361 / 465)$ at week $4,74.2 \%(336 / 453)$ at week $24,77.6 \%(337 / 434)$ at week 48 , and $78.8 \%(327 / 415)$ at week 70 . The overall mean DAS28-CRP change from parent study baseline was $-2.25(n=440)$ at the OLE study baseline, $-2.36(n=463)$ at week $4,-2.41(n=450)$ at week $24,-2.55$ at week $48(n=433)$, and -2.60 at week $70(n=412)$.

Conclusions: In this OLE study of ABP 501, efficacy documented in the parent study was maintained with no new safety findings. Long-term safety, immunogenicity, and efficacy results were similar between subjects who transitioned from adalimumab and those who continued on ABP 501 from the parent study.

Disclosure of Interest: S. Cohen Consultant for: Amgen Inc, J. L. Pablos Consultant for: Amgen Inc, H. Wang Shareholder of: Amgen Inc, Employee of: Amgen Inc, G. Müller Consultant for: Amgen Inc, A. Kivitz Consultant for: Amgen Inc, A. Matsumoto Consultant for: Amgen Inc, E. Krishnan Shareholder of: Amgen Inc, Employee of: Amgen Inc

DOI: 10.1136/annrheumdis-2017-eular.3288

\section{SAT0172 ECONOMIC OUTCOMES, TREATMENT PATTERNS, AND ADVERSE EVENTS AND REACTIONS FOR PATIENTS PRESCRIBED INFLIXIMAB OR CT-P13 IN THE TURKISH POPULATION}

K. Phillips ${ }^{1}$, T. Juday ${ }^{2}$, Q. Zhang ${ }^{3}$, A. Keshishian ${ }^{3} \cdot{ }^{1}$ Vanderbilt University Medical Center, Nashville; ${ }^{2}$ AbbVie Inc., North Chicago; ${ }^{3}$ STATinMED Research, Ann Arbor, United States

Background: CT-P13, a biosimilar drug product to infliximab, was approved and marketed in July 2014 in Turkey. There is little information on the costs, treatment discontinuation and adverse events and reactions between patients who switched from infliximab to CT-P13 and patients who continued infliximab.

Objectives: The study objective was to evaluate health care costs, treatment discontinuation, and adverse events and reactions between patients who switched from infliximab to CT-P13 and patients who continued infliximab in the Turkish population.

Methods: Adult patients with $>1$ claim for infliximab or CT-P13 were identified in a Turkish healthcare administrative database representing $80 \%$ of the Turkish population during the identification period (16 July 2014-31 Aug 2015). Patients were required to continuously use infliximab for $>6$ months with no hospitalizations. Eligible patients either continued on infliximab (index date: date of first infliximab prescription), or switched from infliximab to CT-P13 (index date: switch date). Patients were excluded if they had $>1$ condition with an indication for infliximab during the baseline period. Patients who switched to CT-P13 were 1:10 matched to patients who continued infliximab based on the length of infliximab use prior to the index date. Demographics and clinical characteristics were measured 12 months pre-index date. Generalized linear models were used to compare adjusted health care costs, Cox regression was used to evaluate the adjusted risk of discontinuation, and Poisson regression was used to evaluate the adjusted risk of adverse events and reactions.

Results: The study included 1,524 patients, of whom 1,388 were continuous infliximab users and 136 switched to CT-P13. Ankylosing spondylitis and rheumatoid arthritis were the most common conditions indicated for infliximab and CT-P13; however, patients were much less likely to be switched to CT-P13 for other conditions. After adjusting for demographics and clinical characteristics, patients who switched to CT-P13 had higher outpatient ([Turkish lira] TL 269 vs TL 181; $p=0.005$ ), inpatient (TL 64 vs TL 29; $p=0.313$ ), and pharmacy costs (TL 1,473 vs TL 1,$329 ; p=0.371$, which resulted in significantly higher total health care costs ( $T L 2,009$ vs $T L 1,640 ; p=0.046$ ) compared to patients who continued infliximab. Additionally, patients who switched to CT-P13 were more likely to discontinue treatment (13.2 vs 1.52 per 1000 person-years) compared to those who continued infliximab. Of patients who discontinued CT-P13, 79\% switched back to infliximab. After adjusting for baseline characteristics, patients who switched to CT-P13 were significantly more likely to discontinue treatment compared to those who continued infliximab ( $\mathrm{HR}=5.53 ; 95 \% \mathrm{Cl}: 4.01-7.63)$. There was no difference in the adjusted incidence rate ratio (IRR) between the cohorts for adverse events (IRR=0.67; 95\% Cl: $0.19-2.30$ ) and reactions (IRR $=0.84 ; 95 \% \mathrm{Cl}: 0.55-1.27$ ).

Conclusions: Patients who switched to CT-P13 had significantly higher health care costs and were also more likely to discontinue treatment compared to those who continued infliximab. However, there was no difference in the rate of adverse events and reactions.

Disclosure of Interest: K. Phillips Consultant for: AbbVie Inc., T. Juday Shareholder of: AbbVie Inc., Employee of: AbbVie Inc., Q. Zhang Employee of: STATinMED Research, A. Keshishian Employee of: STATinMED Research

DOI: 10.1136/annrheumdis-2017-eular.2933

\section{SAT0173 SWITCHING FROM REFERENCE PRODUCT ETANERCEPT TO THE BIOSIMILAR SB4 IN A REAL-LIFE SETTING: FOLLOW-UP OF 147 PATIENTS}

V. Sigurdardottir ${ }^{1,2}$, T. Husmark ${ }^{1}$, A. Svärd ${ }^{1,2} \cdot{ }^{1}$ Reumatologkliniken, Falu lasarett; ${ }^{2}$ Centre of Clinical Research Dalarna, Falun, Sweden

Background: The etanercept biosimilar SB4 was introduced in Sweden in early 2016. SB4 has been shown in a randomized controlled trial to be equivalent to its etanercept reference product (ERP) in terms of efficacy and safety in subjects with active rheumatoid arthritis (RA) (1). In light of this, and the fact that biosimilars offer considerable cost savings, all patients being treated with ERP at our clinic were switched to treatment with SB4 in april 2016.

Objectives: To describe the clinical experiences of switching patients on treatment with ERP to SB4 at our clinic.

Methods: All patients using ERP $50 \mathrm{mg}$ at our clinic were identified using the Swedish Rheumatology Quality Register (SRQ). The patients were issued prescriptions for SB4 $50 \mathrm{mg}$ and were sent a letter encouraging them to switch to SB4 when they ran out of ERP. The process of switching was started 21st. However, the actual date of starting treatment with SB4 might have been 0-90 days from April 20th for individual patients, as prescriptions are written in 3 month increments.

Patients were followed up clinically and in the SRQ as planned at the last visit before switching.

For RA and psoriatic arthritis (PsA) patients DAS28 values from the last visit preceding the switch and the last visit after the switch registered up to January 2017 were collected from the SRQ. The paired T-test was used to compare mean DAS28 before and after switching.

Results: Before the switch, 147 patients were on treatment with ERP. Indications for treatment were RA $(\mathrm{N}=76)$, PsA $(\mathrm{N}=28)$, other spondyloarthritis $(\mathrm{N}=13)$, ankylosing spondylitis $(\mathrm{N}=12)$, unspecified arthritis $(\mathrm{N}=10)$ and juvenile arthritis $(\mathrm{N}=8)$.

At the end of January 2017, 126 patients (86\%) were still on SB4.

Since the switch, 9 patients have requested to be switched back to ERP, 2 made the request before initiating therapy with SB4. No objective evidence for lack of efficacy was seen in these 9 patients. Seven patients have stopped treatment with SB4 because of inactive disease. Five patients have been switched to a non-etanercept biologic because of lack of efficacy, these patients also had lack of efficacy when on ERP.

The 76 RA patients had a mean disease duration of 17 years and had been on ERP for a mean duration of 4.7 years. As of January 2017, 60 of the RA patients have been on a follow-up visit and 54 of these had available DAS28 data from both the last visit before and after switching. For the RA patients DAS28 was 2.80 before and 2.79 after switching, $p=0.960$. Complete DAS28 data was available for 23 of the 28 PsA patients, mean DAS28 was 2.54 before switching and 2.06 after, $p=0.161$. The mean duration since switching at follow-up was 22 weeks for the RA and PsA patients.

Conclusions: Switching from the etanercept reference product to the biosimilar SB4 was acceptable to most of our patients. Low mean disease activity has been maintained in the RA and PSA group after the switch.

\section{References:}

[1] Emery P, Vencovsky J, Sylwestrzak A, Leszczynski P, Porawska W, Baranauskaite A, et al. A phase III randomised, double-blind, parallelgroup study comparing SB4 with etanercept reference product in patients with active rheumatoid arthritis despite methotrexate therapy. Annals of the Rheumatic Diseases. 2017;76(1):51-7.

Disclosure of Interest: None declared

DOI: 10.1136/annrheumdis-2017-eular.4391

\section{SAT0174 USE OF A 8-WEEK OBSERVATIONAL PERIOD FOR PREDICTING REMISSION AND LOW DISEASE ACTIVITY AT 52 WEEKS IN RA PATIENTS TREATED WITH CERTOLIZUMAB PEGOL - A MULTICENTER STUDY}

Y. Kanayama ${ }^{1}$, A. Kaneko ${ }^{2}$, N. Takahashi ${ }^{3}$, T. Kato ${ }^{4}$, M. Hayashi ${ }^{5}$, Y. Hattori ${ }^{2}$, N. Asai ${ }^{3}$, N. Ishiguro ${ }^{3}$, T. Kojima ${ }^{3}$ on behalf of TBCR study group. ${ }^{1}$ Orthopedic Surgery and Rheumatology, Toyota Kosei Hospital, Toyota; ${ }^{2}$ Orthopedic Surgery and Rheumatology, Nagoya Medial Center; ${ }^{3}$ Orthopedic Surgery, Nagoya University Graduate school of Medicine, Nagoya; ${ }^{4}$ Orthopedic Surgery, Kato clinic, Okazaki; ${ }^{5}$ Orthopedic Surgery and Rheumatology, Nagano Red Cross Hospital, Nagano, Japan

Background: Certolizumab pegol (CZP) is a polyethylene glycol (PEG)ylated Fc-free new anti-TNF $\alpha$ agent. However few data still reported clinical efficacy of CZP treatment in the routine practice.

Objectives: This study aimed to provide clinical evidence of an adequate observational period for predicting remission and low disease activity (LDA) achievement at 52 weeks in RA patients treated with Certolizumab pegol (CZP). Methods: Patients with a diagnosis of RA according to the 2010 ACR/EULAR criteria who had been prescribed CZP from Tsurumai Biologics Communication Registry (TBCR) between May 2013 and October 2015 were enrolled.The final study cohort of 98 Japanese RA patients. We reviewed the methods about the improvement of DAS28-ESR and SDAl which was an index of disease activity of RA using Wilcoxon signed-rank test and the rate of remission and LDA patients at 
Week4, 8, 12, 24 and 52 by LOCF method. Also we used ROC analysis in order to determine the optimal period to achieve remission for the DAS-ESR and SDAI at Week52.

Results: The group of patients included 16 males and 82 females. The mean age was $59.5 \pm 14.7$ years old; the disease duration was $9.4 \pm 8.8$ years; the patients of receiving methotrexate (MTX) was 73 cases (74\%); the MTX dose was $11.2 \pm 3.6 \mathrm{mg} /$ week and b-DMARD naïve patients was 57 cases $(61 \%)$. Clinical findings related to RA were as follows: mean tender joint count, $5.2 \pm 4.7$; swollen joint count, 5.0 \pm 4.0 ; patient's and physician's global assessment of disease activity, $48.9 \pm 27.4$ and $42.3 \pm 23.2 \mathrm{~mm}$; CRP, $1.9 \pm 2.2 \mathrm{mg} / \mathrm{dL}$; ESR, $47.4 \pm 34.0$ $\mathrm{mm} / \mathrm{h}$; MMP3, $233 \pm 186 \mathrm{ng} / \mathrm{ml}$; the rate of rheumatoid factor positive patients was $78 \%$; DAS28 (ESR), 4.84 \pm 1.36 ; and SDAI, 21.2 \pm 11.3 . The mean DAS-ESR improved to $3.54 \pm 1.35,3.31 \pm 1.46,3.37 \pm 1.47$ and $3.31 \pm 1.43$ at Week $4,12,24$ and $52(p<0.001, p<0.001, p<0.001, p<0.001)$ and the mean SDAl improved to $11.4 \pm 9.0,9.7 \pm 9.0,9.8 \pm 9.1$ and $9.4 \pm 9.1$ at Week $4,12,24$ and $52(p<0.001$, $\mathrm{p}<0.001, \mathrm{p}<0.001, \mathrm{p}<0.001$ ) significantly (Fig.1). At Week 4, 12, 24 and 52 the rate of patients who achieved remission were each $28.8,37.2,32.9,33.7 \%$ and $11.7,29.3,30.5,28.8 \%$ in DAS-ESR and SDAl criteria (Fig.2). Also at Week $4,12,24$ and 52 the rate of patients who achieved low disease activity (LDA) were each $46.6,53.2,51.2,55.8 \%$ and $58.8,64.1,65.9,71.3 \%$ in DAS-ESR and SDAI criteria. Areas under the receiver operating characteristic curves for the DAS28-ESR and SDAI at each time point for remision achievement at 52 weeks were each 0.578 and 0.702 at baseline, 0.755 and 0.822 at week4, 0.821 (cut-off index 2.73 , odds ratio 16.7 , sensitivity 0.75 , specificity, 0.85 ) and 0.856 (cut-off index 5.30 , odds ratio 29.6 , sensitivity 0.86 , specificity, 0.82 ) at week 8 , and 0.820 and 0.809 at week 12
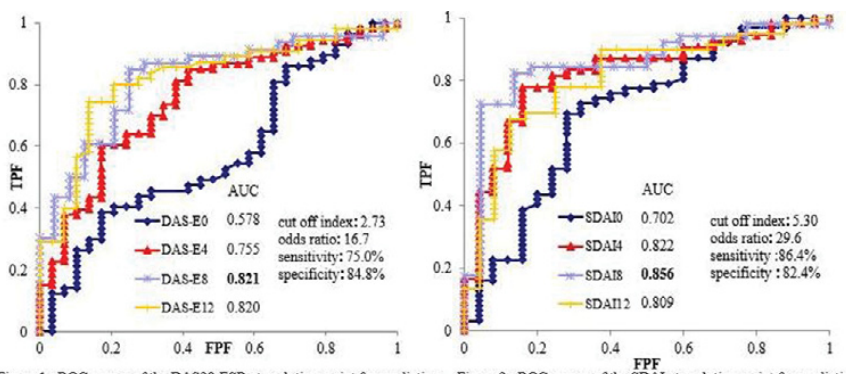

Figure 1: ROC curves of the DAS2s-ESR at each time point for predicting Figure $2:$ ROC curves of the SDA AI at each time point for predicting

Conclusions: The new TNF-antagonist therapy of CZP was effective early and rapidly in patients with active Japanese RA. This study suggested that eight weeks is an adequate optimal period to judge whether the achieved remission or not at Week 52

Disclosure of Interest: Y. Kanayama: None declared, A. Kaneko Speakers bureau: Mitsubishi Tanabe Pharma, Takeda Pharma, Eisai Pharma, Chugai Pharma, Abbott, Bristol-Myers Squibb, UCB, Janssen, and Pfizer, N. Takahashi Speakers bureau: Abbvie Japan Co. Ltd, Eisai Co. Ltd, UCB Japan Co. Ltd, MitsubishiTanabe Pharma Corporation, Takeda Pharmaceutical Company Ltd, Pfizer Co. Ltd, Chugai Pharmaceutical Co. Ltd, Janssen Pharmaceutical K.K., and, T. Kato: None declared, M. Hayashi: None declared, Y. Hattori: None declared, N. Asai: None declared, N. Ishiguro Grant/research support from: Daiichi Sankyo, Takeda Pharmaceutical, Hisamitsu Pharmaceutical, Otsuka Pharmaceutical, Taisho Toyama Pharmaceutical, Kaken Pharmaceutical, Eisai, Janssen Pharmaceutical, Bristol- Myers Squibb, AbbVie, Chugai Pharmaceutical, Mitsubishi Tanabe Pharmaceutical, Astellas Pharma, and Pfizer Japan, Speakers bureau: Daiichi Sankyo, Takeda Pharmaceutical, Hisamitsu Pharmaceutical, Otsuka Pharmaceutical, Taisho Toyama Pharmaceutical, Kaken Pharmaceutical, Eisai, Janssen Pharmaceutical, Bristol-Myers Squibb, AbbVie, Chugai, T. Kojima Speakers bureau: Mitsubishi Tanabe Pharma, Takeda Pharma, Eisai Pharma, AbbVie, Bristol-Myers Squibb, and Pfizer, Janssenn Pharmaceutical Companies, Astellas Pharma and Chugai Pharma

DOI: 10.1136/annrheumdis-2017-eular.4653

\section{SAT0175 A DESCRIPTIVE ANALYSIS OF REAL-WORLD TREATMENT PATTERNS IN A TURKISH RHEUMATOLOGY POPULATION THAT CONTINUED INNOVATOR INFLIXIMAB (REMICADE) THERAPY OR SWITCHED TO BIOSIMILAR INFLIXIMAB}

Y. Yazici ${ }^{1}$, L. Xie ${ }^{2}$, A. Ogbomo ${ }^{2}$, D. Parenti ${ }^{3}$, K. Goyal ${ }^{3}$, A. Teeple ${ }^{3}$, L. Ellis ${ }^{3}$ I. Simsek ${ }^{4}{ }^{1}$ New York University Hospital for Joint Diseases, New York; ${ }^{2}$ STATinMED Research Inc, Ann Arbor; ${ }^{3}$ Janssen Scientific Affairs, LLC, Horsham, United States; ${ }^{4}$ Guven Hospital, Ankara, Turkey

Objectives: This study examined treatment patterns in a rheumatology patient (pt) population initially prescribed innovator infliximab (IFX) that either switched to biosimilar infliximab (CT-P13) or continued on IFX following availability of CT-P13 in the Turkish healthcare system.

Methods: Adult pts with $\geq 1$ diagnosis code (ICD-10-CM M05.X; M06.X) for rheumatoid arthritis (RA) and a prescription for IFX were identified in a national Turkish health care database during the study period (01DEC2010-01DEC2015). Eligible pts were those who continued on IFX (Continuers cohort; CC) or switched from IFX to CT-P13 (Switchers cohort; SC) during the identification period; had continuous medical/pharmacy benefit enrollment $\geq 12$ months before and $\geq 6$ months after the index date (date of switch for SC and a random IFX prescription date for (C); had a prescription claim for IFX within 16 weeks of the index date during the baseline period. Demographics, concomitant disease, medications, and treatment patterns (dose, refill interval, discontinuation, and switch) were summarized. A confirmed discontinuation was defined as a switch to another biologic medication or the absence of an index biologic claim for $\geq 120$ days without censoring. Patient weight was unavailable in the dataset.

Results: Key results are shown in the Table. A total of 3018 pts met study criteria. The majority $(95 \%$; $n=2870$; CC) continued on IFX and had a mean age of 44 years; $46 \%$ were female and mean follow up of 12 months. A total of 148 pts (5\%) switched to CT-P13 (SC) and had mean age of 44 years; $51 \%$ female and mean follow up of 9 months. Approximately $40 \%$ of pts in each cohort had a concomitant diagnosis for ankylosing spondylitis (AS; Table). Other concomitant diseases and medications appeared balanced between cohorts. In the CC, pts had an average of 4.7 infusions at a mean dose of 4.4 vials approximately every 10 weeks. In the SC, pts had an average of 2.6 infusions at a mean dose of 3.6 vials approximately every 10 weeks. Therapy discontinuation occurred in $38 \%$ in the CC; average time to any discontinuation or censoring of IFX was 256 days (Table). In the SC, CT-P13 discontinuation was observed in $82 \%$; average time to any discontinuation or censoring of CT-P13 was 124 days; $74 \%$ of SC switched to another biologic with $94 \%$ of these returning to IFX.

\begin{tabular}{|c|c|c|c|c|}
\hline & \multicolumn{2}{|c|}{$\begin{array}{l}\text { Switchers Cohort } \\
(\mathrm{N}=148)\end{array}$} & \multicolumn{2}{|c|}{$\begin{array}{l}\text { Continuers Cohort } \\
(N=2870)\end{array}$} \\
\hline & N/Mean & $\% / S D$ & N/Mean & $\% / S D$ \\
\hline Age (Mean) (years) & 44 & 13 & 44 & 12 \\
\hline \multicolumn{5}{|l|}{ Gender } \\
\hline Female & 75 & $51 \%$ & 1,332 & $46 \%$ \\
\hline Average Length of Follow up Period (in Months) & 9 & 2 & 12 & 3 \\
\hline \multicolumn{5}{|l|}{ Concomitant Disease During Baseline Period } \\
\hline Ankylosing Spondylitis & 73 & $49 \%$ & 1,214 & $42 \%$ \\
\hline Psoriatic Arthritis or Psoriasis & 19 & $13 \%$ & 582 & $20 \%$ \\
\hline Crohn's Disease & 6 & $4 \%$ & 191 & $7 \%$ \\
\hline Ulcerative Colitis & 8 & $5 \%$ & 157 & $5 \%$ \\
\hline \multicolumn{5}{|l|}{ Concomitant RA-Medications During Follow-Up Period } \\
\hline Methotrexate & 31 & $21 \%$ & 652 & $23 \%$ \\
\hline Sulfasalazine & 21 & $14 \%$ & 340 & $12 \%$ \\
\hline \multicolumn{5}{|l|}{ Dosing Characteristics } \\
\hline Average \# of doses within follow up period & 2.6 & 1.6 & 4.7 & 2.4 \\
\hline Mean \# of weeks between doses & 10.1 & 5.1 & 9.9 & 3.8 \\
\hline Mean \# of days between 1 st and $2^{\text {nas }}$ dose & 75 & 48 & 70 & 34 \\
\hline Mean $\#$ of days between 2 nd and $3 r d$ dose & 72 & 38 & 70 & 29 \\
\hline Mean \# of days between $3 r d$ and 4th dose & 65 & 31 & 67 & 26 \\
\hline Mean \# of vials per Infusion & 3.6 & 1.6 & 4.4 & 1.9 \\
\hline \multicolumn{5}{|l|}{ Switching } \\
\hline$\#$ and $\%$ of patients with 21 switch & 110 & $74 \%$ & 471 & $16 \%$ \\
\hline$\%$ of Primary Switches from CT-P13 to IFX & 103 & $94 \%$ & NA & NA \\
\hline \multicolumn{5}{|l|}{ Discontinuation } \\
\hline \# of Patients Confirmed to Have Discontinued & 121 & $82 \%$ & 1,089 & $38 \%$ \\
\hline Time to confirmed discontinuation (days) & 94 & 58 & 126 & 91 \\
\hline Time to any discontinuation or censoring (days): & 124 & 87 & 256 & 138 \\
\hline
\end{tabular}

Conclusions: This study shows switching from IFX to CT-P13 was infrequent. However, in those switching to CT-P13, a high percentage (82\%) of CT-P13 discontinuation was observed and the majority returned to IFX. Further studies are needed to understand the reasons for these observations.

Disclosure of Interest: Y. Yazici Grant/research support from: Janssen Scientific Affairs, LLC, L. Xie Consultant for: Janssen Scientific Affairs, LLC, A. Ogbomo Consultant for: Janssen Scientific Affairs, LLC, D. Parenti Employee of: Janssen Scientific Affairs, LLC, K. Goyal Employee of: Janssen Scientific Affairs, LLC, A. Teeple Employee of: Janssen Scientific Affairs, LLC, L. Ellis Employee of: Janssen Scientific Affairs, LLC, I. Simsek Grant/research support from: Janssen Scientific Affairs, LLC

DOI: 10.1136/annrheumdis-2017-eular.1128

\section{SATURDAY, 17 JUNE 2017}

Rheumatoid arthritis - other biologic treatment

\section{SAT0176 PATTERNS OF BIOLOGIC DMARD MONOTHERAPY IN A LARGE NATIONWIDE RHEUMATOID ARTHRITIS COHORT: DATA FROM 1036 PATIENTS}

K. Thomas ${ }^{1}$, E. Kaltsonoudis ${ }^{2}$, A. Drosos ${ }^{2}$, I. Papalopoulos ${ }^{3}$, P. Sidiropoulos ${ }^{3}$, P. Katsimbri ${ }^{1}$, D. Boumpas ${ }^{1}$, P. Tsatsani ${ }^{4}$, S. Gazi ${ }^{4}$, E.P. Grika ${ }^{1}$,

P.G. Vlachoyiannopoulos ${ }^{1}$, K. Fragiadaki ${ }^{1}$, M. Tektonidou ${ }^{1}$, P.P. Sfikakis ${ }^{1}$, K. Karagianni ${ }^{1}$, L.I. Sakkas ${ }^{5}$, L. Pantazi ${ }^{6}$, K. Boki ${ }^{6}$, T. Dimitroulas ${ }^{7}$,

A. Garyfallos ${ }^{7}$, D. Kasimos ${ }^{8}$, G. Evangelatos ${ }^{9}$, A. lliopoulos $^{9}$, C. Georganas ${ }^{10}$, P. Vounotrypidis ${ }^{10}$, M. Areti $^{10}$, P. Georgiou ${ }^{11}$, K. Delis $^{10}, \mathrm{~K}_{\text {. Mavragani }}{ }^{1}$, I. Bournazos ${ }^{10}$, G. Katsifis ${ }^{12}$, C. Mavromatis ${ }^{10}$, G.D. Kitas ${ }^{13}$, D. Vassilopoulos ${ }^{1}$ 